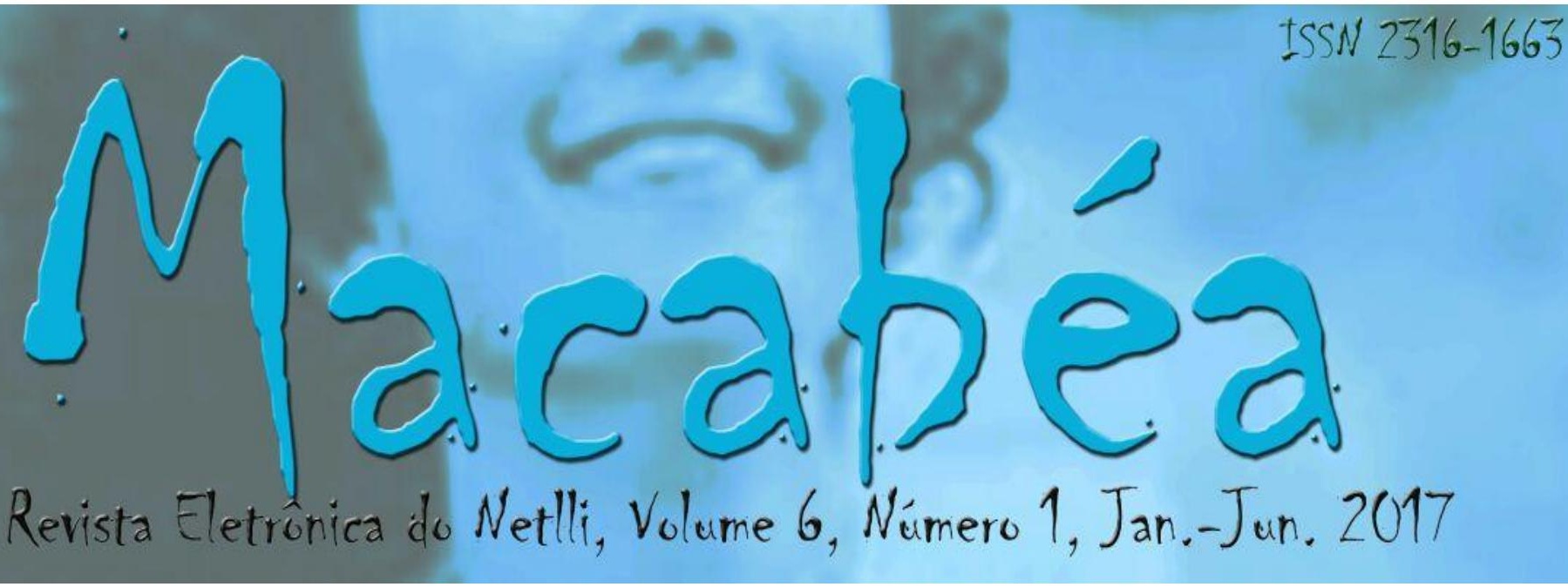

\title{
CRONOTOPO NA POÉTICA DE MANOEL DE BARROS
}

\section{CHRONOTOPO IN THE POETRY OF MANOEL DE BARROS}

\author{
SILVA, José Ronaldo Ribeiro da(IFCE) \\ MOREIRA, Maria Efigênia Alves(IFCE) \\ BARROS, Ileane Oliveira(IFCE) \\ LIMA, José Rômulo Porfírio de(IFCE)
}

RESUMO | INDEXAÇÃO | TEXTO | REFERÊNCIAS | CITAR ESTE ARTIGO | OS AUTORES

RECEBIDO EM 06/01/2017 • APROVADO EM 31/01/2017

\section{Abstract}

Literary criticism recognizes that Bakhtin is not the founder of the concept of chronotopy. The Russian master borrowed the term from Einstein's concepts of mathematics and Einstein's theory of relativity, although he was supported epistemologically by the figure of Kant and his followers. Bakhtin's merit lies in the "metaphorization" of the concept he applied to literary studies to designate the inseparable relationship between space and time. The concept of chronotope, in Bakhtin, first appears in the text Forms of Time and of the Chronotope in the Novel Notes toward a Historical Poetics and, later, in Aesthetics of verbal creation, in the chapter titled The Novel of Educationand its Significance in the History of Realism. We use this Bakhtinian framework of indissibility of space and time to analyze aspects of Manoel de Barros' poetics. This literary mark crosses the poet's poetics and can be considered as one of his specific aesthetics. Thus, the present work seeks to find out how Manoel de Barros elaborates his chronotopic aesthetics through his creative-contemplative look. 
Resumo

A crítica literária reconhece que Bakhtin não é o fundador do conceito de cronotopia. 0 mestre russo tomou emprestado o termo a partir de conceitos da matemática e da teoria da relatividade de Einstein, apesar de se apoiar epistemologicamente na figura de Kant e seus seguidores. Seu mérito está na "metaforização" do conceito que ele aplicou aos estudos literários para designar a relação indissociável entre o espaço e o tempo. 0 conceito de cronotopo em Bakhtin aparece primeiramente no texto formas de tempo e de cronotopo no romance - ensaios de poética histórica e, depois, em Estética da criação verbal, no capítulo intitulado o romance de educação na história do realismo. Utilizamos esse arcabouço bakhtiniano de indissiciabilidade de espaço e tempo para analisar aspectos da poética de Manoel de Barros. Essa marca literária trespassa a poética do poeta e pode ser considerada uma estética específica dele. Destarte, o presente trabalho busca averiguar como Manoel de Barros elabora sua estética cronotópica através do olhar criativo-contemplativo.

Entradas para indexação

KEYWORDS: Chronotope. Aesthetics. Manoel de Barros..

PALAVRAS-CHAVECronotopo. Estética. Manoel de Barros

\section{Texto integral}

\section{INTRODUÇÃO}

Ao propor a existência de um relacionamento indissociável entre as dimensõ es de espaço e tempo no texto literário de François Rabelais, Bakhtin (1992, 1998) provoca uma novidade no universo dos estudos literários. A partir de suas leituras sobre as concepções espaço-temporais de Einstein, o mestre russo oferece não apenas um novo elemento estético a ser observado como também uma categoria analítica profícua: o cronotopo.

A mesclagem das dimensões de tempo e lugar designada pelo termo, não de sua criação, mas adaptado pelo pensador, ainda é uma das categorias relativamente pouco abordadas pelos estudiosos bakhtinianos, principalmente por aqueles que o utilizam como fundamentação teórica para as análises linguísticas. Categorias como gêneros textuais, polifonia, carnaval, ideologia, enunciado, palavra, tema e significação, esferas discursivas, formas de citação da palavra alheia, tem recebido mais atenção dos linguistas em geral, principalmente por terem deslocado as análises linguísticas dos ideais estruturalistas e imanentes saussureanos para um enfrentamento dialógico, sócio-histórico e interativo da linguagem. 
A categoria do cronotopo, proposta pela primeira vez pelo mestre russo, não surgiu a priori. Assim como ocorreu com a categoria da polifonia, elucidada após vasta leitura de Bakhtin das obras do grande autor Dostoiévski, com as categorias de grotesco, do riso e do carnaval, a partir de suas leituras de Rabelais, e com a categoria da citação do discurso alheio, de leituras variadas do russo, do alemão e do francês, a categoria cronotopo só ganha vida no pensamento bakhtiniano a partir da leitura de Rabelais e outros autores como Goethe. Em outras, palavras, para aqueles que pretendem analisar textos dentro da abordagem bakhtiniana, é preciso o debruçamento sobre os textos, levando-se em consideração suas condições de produção externas e seu teor formal-conteudístico interno.

No que se refere à poética barrosiana, buscamos demonstrar como as dimensões de espaço e tempo e relacionam artisticamente, revelando a estética do poeta enquanto elemento criativo a partir da imaginação da criança. Em Barros, a estética criativa está atravessada completamente pelo absurdo e delírio infantil, condição sine qua non da produção do artista.

Para demonstrar esse universo cronotópico e estético em Manoel de Barros, analisamos quatro poemas: A menina avoada, 0 muro, Uma didática da invenção e Desejar ser. 0 trabalho começa com uma abordagem teórica sobre a categoria em análise dentro do escopo do pensamento bakhtiniano e de pensadores pósbakhtinianos, inclusive com problematizações do pensamento do precursor russo. Em seguida, buscamos demonstrar a inter-relação entre as dimensões de espaço e tempo dentro de quatro poemas de Barros, atravessados pela estética criativa da infância, vista como grande tempo-lugar de imaginação e criação poética.

\section{O CRONOTOPO BAKHTINIANO}

O termo cronotopo foi introduzido nos estudos literários por Bakhtin. Todavia, não se trata de uma expressão criada pelo mestre russo. 0 próprio Bakhtin (1998) afirma que o termo é empregado na área dos estudos matemáticos e fora "emprestado" da teoria da relatividade de Einstein. Bakhtin fez, então, uma transplantação, quase que um processo de metaforização, segundo o próprio autor, para, a partir de tal termo, designar um fenômeno literário encontrado, principalmente, nos romances de François Rabelais.

Nós daremos o nome de cronotopo (literalmente, "espaço-tempo") para a ligação intrínseca das relações temporais e espaciais que são artisticamente expressas na literatura. Este termo (tempo-espaço) é empregado em matemática, e foi introduzido como parte da Teoria da Relatividade de Einstein. 0 significado especial que ela tem na teoria da relatividade não é importante para nossos propósitos, estamos tomandoo emprestado para a crítica literária quase como uma metáfora (quase, mas não totalmente). 0 que conta para nós é o fato de que ele expressa a 
inseparabilidade do espaço e do tempo (tempo como a quarta dimensão do espaço). (BAKHTIN, [1975] 1988: 84)

Segundo Amorim (2006, p. 102), o termo cronotopo, no escopo do pensamento bakhtiniano, se refere à "indissolubilidade da relação entre o espaço e o tempo". Esse conceito é discutido nos livros Estética da criação verbal (1992), no texto 0 romance de educação na história do Realismo e no texto "Formas de tempo e de cronotopo no romance”, do livro Questões de literatura e estética (1988).

Bakhtin (1998, p. 312), mesmo apresentando o cronotopo enquanto relação indissociável entre espaço e tempo, afirma que o tempo é o principal condutor da categoria. Desta forma, o tempo é posto como precípuo enquanto o espaço é relegado à condição de figurante no binômio. A partir desse fato, uma leitura mais crítica da obra do mestre russo pode questionar o porquê da primazia do tempo em detrimento do espaço. Holquist (2002, p. 107) afirma que a categoria "se refere a combinações particulares de tempo e espaço que resultaram em formas narrativas historicamente manifestadas ${ }^{1 "}$. (Tradução nossa).

Todavia, a despeito da reclamada valorização do tempo em relação ao espaço, Bakhtin afirma que:

Aqui o tempo condensa-se, comprime-se, torna-se artisticamente visível; o próprio espaço intensifica-se, penetra no movimento do tempo, do enredo e da história. Os índices do tempo transparecem no espaço, e o espaço reveste-se de sentido e é medido com o tempo. Esse cruzamento de séries e a fusão de sinais caracterizam o cronotopo artístico (1998, p.211).

O que se sobressai e este é o aspecto mais relevante do cronotopo é a intersecção entre os índices de espaço e de tempo. Destarte, a despeito de eventuais críticas quando ao balanceamento das duas categorias dentro do binômio, não se deve negar a Bakhtin o que a ele pertence. E o mérito do mestre russo foi flagrar, a partir de cuidadosas análises de textos literários, uma nova categoria teórica que permitiu um novo olhar analítico sobre a literatura. Como ocorreu com outras categorias, hoje amplamente aceitas, criticadas, visitadas e revisitadas pela academia, o conceito de cronotopo surge da análise de dados linguísticos concretos, sejam enunciados literários, cotidianos, etc.

Bakhtin falará do conceito de polifonia, por exemplo, depois de flagrá-lo na obra de Dostoiévski; abordará o carnaval e o grotesco a partir da leitura de textos de François Rabelais; sua abordagem das formas de citação da palavra alheia ou discurso citado, embasa-se em leituras de autores russos, alemães e franceses, e assim por diante. É preciso ressaltar, no pensamento bakhtiniano, essa característica inerente à sua produção: não há categorias prévias a serem aplicadas a um corpus ou corpora. As leituras e análises precedem as denominações e estabelecimentos de categorias flagradas em certos enunciados. E não foi diferente com a categoria do cronotopo. 
Uma outra característica do cronotopo bakhtiniano é seu aspecto concreto e imediato. Diferentemente de Kant, que possuía uma visão imanente, transcendental das dimensões do tempo e do espaço, Bakhtin elabora um conceito relacionado à realidade. Isso se dá porque o autor explica o cronotopo enquanto fenômeno criador de tipicidades narrativas, ou seja, idiossincrasias sócio-históricas. Diferentes épocas e espaços se refletem em obras artisticamente elaboradas através do filtro criativo do artista. É por isso que é possível falar em cronotopo rabelaisiano e em cronotopo barrosiano. Tempo e espaço artisticamente entrelaçados é o que configura as idiossincrasias cronotópicas.

\section{O CRONOTOPO EM MANOEL DE BARROS}

A poética de Manoel de Barros apresenta uma estética muito específica quanto à relação entre espaço e tempo. 0 poeta, consegue entrecruzar as duas dimensões artisticamente com a temática da infância, que se parece materializar o tempo-espaço em um elemento único. Com ele, o tempo se concretiza no espaço e o espaço reflete as marcas do tempo da infância, elemento estético quase sempre presente em seus poemas narrativos. Manoel de Barros criou uma estética cronotópica bastante específica (SILVEIRA e AXT, 2015, p. 189 - 206). Escolhemos quatro poemas de Barros para demonstrar como ele trabalha o cronotopo segundo sua estética da infância enquanto elemento de liberdade de imaginação e criação. Vejamos um poema que trabalha com forte entrelaçamento de tempo e espaço:

\section{A MENINA AVOADA}

Foi na fazenda de meu pai antigamente. / Eu teria dois anos; meu irmão, nove. / Meu irmão pregava no caixote duas rodas de lata de goiabada. / A gente ia viajar. / As rodas ficavam cambaias debaixo do caixote: / Uma olhava para a outra. / Na hora de caminhar as rodas se abriam para o lado de fora. / De forma que o carro se arrastava no chão. / Eu ia pousada dentro do caixote com as perninhas encolhidas. / Imitava estar viajando. / Meu irmão puxava o caixote por uma corda de embira. / Mas o carro era diz-que puxado por dois bois. / Eu comandava os bois: / - Puxa, Maravilha! / -Avança, Redomão! / Meu irmão falava que eu tomasse cuidado porque / Redomão era coiceiro. / As cigarras derretiam a tarde com seus cantos. / Meu irmão desejava alcançar logo a cidade / Porque ele tinha uma namorada lá. / A namorada do meu irmão dava febre no corpo dele. / Isso ele contava. / No caminho, antes, a gente precisava de atravessar um rio inventado. / Na travessia o carro afundou e os bois morreram afogados. / Eu não morri porque o rio era inventado. / Sempre a gente só chegava no fim do quintal. / E meu irmão nunca via a namorada dele. / Que diz-que dava febre em seu corpo. 
Neste poema-narrativa, Barros utiliza como pano de fundo para as aventuras de criança, o quintal, espaço muito recorrente em sua poética. É o espaço associado ao tempo de infância que cria toda a estética do poema. A imaginação dos irmãos com seu carrinho improvisado, a viagem para a cidade em busca da namoradinha do irmão que lhe causava "febre no corpo", os bois Maravilha e Redomão, um rio que precisava ser atravessado, a morte dos animais, são elementos que só são criados a partir da imaginação/liberdade que as crianças possuem no espaço-tempo do quintal, tempo em que os elementos reduzidos (carro, quintal etc.) são expandidos em elementos maiores e tempos maiores (cidade, rio, travessia, viagem etc.).

No poema abaixo, Barros escolhe um muro do tempo de infância para relacionar seu espaço-tempo, sempre atrelado à estética da criação/imaginação da infância.

\title{
O MURO
}

\begin{abstract}
Não possuía mais a pintura de outros tempos. / Era um muro ancião e tinha alma de gente. / Muito alto e firme, de uma mudez sombria. / Certas flores do chão subiam de suas bases / Procurando deitar raízes no seu corpo entregue ao tempo. / Nunca pude saber o que se escondia por detrás dele. / Dos meus amigos de infância, um dizia ter violado tal segredo, / E nos contava de um enorme pomar misterioso. / Mas eu, eu sempre acreditei que o terreno que ficava atrás do muro era um terreno abandonado!
\end{abstract}

O poema sincroniza com perfeição as dimensões de tempo e espaço. 0 muro em si é considerado um lugar-tempo-pessoa. 0 autor trata o muro como "ancião" com "alma de gente". Além disso, o objeto é cercado pela mística infantil do mistério e cercado de curiosidades, como se fosse um portal sagrado que levasse a algum outro lugar maravilhoso. Seria um pomar? O poeta-narrador acreditava se tratar de um terreno abandonado. Enfatiza mais o muro do que o além-muro. Diz o poeta que a imponente ruína tem seu corpo "entregue ao tempo". 0 muro é o elemento espacial que, carinhosamente tratado como gente, remete automaticamente ao tempo de infância do poeta.

No poema a seguir, claro diálogo com o texto bíblico do Evangelho de João, o elemento sincronizador de tempo e espaço é o verbo, atravessado pela liberdade de imaginação/criação da infância. É a criança que possui o dom de fazer o verbo delirar, e é nesse delírio que ocorrem os nascimentos.

No descomeço era o verbo. / Só depois é que veio o delírio do verbo. / O delírio do verbo estava no começo, lá onde a criança diz: Eu escuto a cor dos passarinhos. / A criança não sabe que o verbo escutar não funciona para cor, mas para som. / Então se a criança muda a função de um verbo, ele delira. / E pois. / Em poesia 
que é voz de poeta, que é a voz de fazer nascimentos - / 0 verbo tem que pegar delírio.

O verbo em si é um descomeço. O verdadeiro início de tudo, da criação, somente acontece com o delírio. E essa capacidade de fazer o verbo delirar irrompe na imaginação/criação da criança, único ser capaz de causar sinestesias sinceras, como mudar as funções de "escutar", que é para ouvir em função de visão, vislumbrando cores. 0 poeta arremata sua aula de didática poética afirmando que o poeta precisa fazer o verbo delirar, tal qual a criança o faz, caso contrário não ocorrem os nascimentos, não há poesia.

Neste poema, a infância é um tempo-lugar completamente indissociável. Se é nessa época da vida que a poesia realmente acontece, através do mecanismo do delírio verbal, o próprio autor diz que "O delírio do verbo estava no começo, lá onde a criança diz: Eu escuto a cor dos passarinhos". 0 começo, segundo o poeta é exatamente o a criança. Ela encarna o tempo e o lugar perfeito para o delírio e, consequentemente, para a criação poética. A estética de Manoel de Barros fica explícita nesse poema. Essa estética é retomada no poema a seguir:

DESEJAR SER 6.

Carrego meus primórdios num andor. / Minha voz tem um vício de fontes. / Eu queria avançar para o começo. / Chegar ao criançamento das palavras. / Lá onde elas ainda urinam na perna. / Antes mesmo que sejam modeladas pelas mãos. / Quando a criança garatuja o verbo para falar o que não tem. / Pegar no estame do som. / Ser a voz de um lagarto escurecido. / Abrir um descortínio para o arcano.

0 poeta trata seus "primórdios" enquanto objeto valoroso. Tão valoroso que deve ser carregado em um andor. Nesse sentido, mais uma vez, Barros explicita que sua estética está completamente vinculada ao "criançamento das palavras". Sem a intervenção estética da criança, do lugar chamado "criançamento", "lá onde elas ainda urinam na perna", o poeta não prevê criação artística. A infância, é valorizada enquanto tempo-lugar-objeto ideal para a criação do poeta.

\section{CONCLUSÃo}

A infância barrosiana é considerada uma época e em muitos aspectos, um lugar privilegiado de produção artística. 0 poeta se refere a essa fase da vida com termos como "lá", indicando que, ao menos na linha do tempo, se trata de um espaço, de um lugar-fonte, de onde emanam as melhores condições de criação artística.

Tempo-espaço, infância, imaginação, poesia e criatividade são intrinsecamente sincronizadas por Barros. Para o poeta, o tempo -espaço da infância é fundamental para a transformação da palavra em poesia legítima, sincera, como o 
autor menciona no seu poema Uma didática da invenção. 0 tempo barrosiano se materializa na infância; a infância é vista como lugar. A estética barrosiana só se revela à luz da infância enquanto tempo-lugar de criação.

A estética de Barros alinha-se com o pensamento de Bakhtin sobre o cronotopo, mas, além disso, é preciso ressaltar a valorização que o poeta atribui à infância como elemento-fonte de sinceridade e essência artística. Desta forma, mesmo em uma produção poética, o autor consegue amalgamar o espaço-tempo de forma indissociável através da liga imprescindível da visão/imaginação da criança. Neste sentido, o poeta explicita mais que uma estética específica; retrata um posicionamento axiológico de valor e de um fazer legítimo da arte.

\section{Notas}

1 "[...] it refers to particular combinations of time and space as they have resulted in historically manifested narrative forms".

Referências

AMORIM, M. Cronotopo e exotopia. In Brait, B. (org.). Bakhtin: outros conceitoschave. São Paulo: Contexto, 2006.

BAKHTIN, M. Estética da criação verbal. São Paulo: Martins Fontes, 1992.

Questões de literatura e estética. São Paulo: Unesp, 1998.

BARROS, M. Poesia completa. São Paulo: Leya, 2010.

HOLQUIST, M. Forms of time and of the chronotope in the novel. In: BAKHTIN, M. The dialogic imagination: four essays. Trad. Caryl Emerson, Michael Holquist. Austin: University of Texas Press, [1975] 1988, p. 84 a 258.

. Dialogism: Bakhtin and his world. Psychology Press, 2002.

SILVEIRA, P. D.; AXT, M. Mikhail Bakhtin and Manoel de Barros: between Chronotope and Childhood. Bakhtiniana, São Paulo, 10 (1): 189 - 206, Jan/April, 2015.

Para citar este artigo

LIMA, José Rômulo Porfírio de; BARROS, Ileane Oliveira; MOREIRA, Maria Efigênia Alves; SILVA, José Ronaldo Ribeiro da. Cronotopo na poética de Manoel de Barros. Macabéa Revista Eletrônica do Netlli, Crato, v. 6, n. 1, p. 1-9, jan.-jun. 2017. 
José Ronaldo Ribeiro da Silva tem graduação em Letras e Especialização em Ensino de Língua Inglesa pela Universidade Regional do Cariri - URCA

Maria Efigênia Alves Moreira atualmente faz mestrado profissional em Ciências da Educação e Multidisciplinaridade, pela Faculdade do Norte do Paraná (em processo de conclusão) e mestranda em Literatura Comparada na Universidade Federal do Ceará - UFC.

Ileane Oliveira Barros atualmente é professora no curso de Licenciatura em Ciências Biológicas do Instituto Federal de Educação, Ciência e Tecnologia do Ceará no Campus Jaguaribe.

José Rômulo Porfírio de Lima graduado em Letras pela Universidade Estadual do Ceará (2011) 